\title{
Improvement of sliding mode power control applied to wind system based on doubly-fed induction generator
}

\author{
Btissam Majout, Douae Abrahmi, Yasmine Ihedrane, Chakib El Bakkali, Karim Mohammed, \\ Badre Bossoufi \\ LIMAS Laboratory, Faculty of Sciences Dhar El Mahraz, Sidi Mohamed Ben Abdellah University, Fez, Morocco
}

\begin{tabular}{|c|c|}
\hline Article Info & ABSTRACT \\
\hline Article history: & In this work, we are interested in improving the performance of a doubly-fed \\
\hline Received May 19, 2020 & $\begin{array}{l}\text { induction generator (DFIG) based wind system, by applying a sliding mode } \\
\text { control strategy. The objective is the regulation of the active and reactive }\end{array}$ \\
\hline Revised Dec 20, 2020 & power, also the voltage and the frequency of the signal injected into the \\
\hline Accepted Jan 19, 2021 & distribution network. The model proposed for the control is based on the \\
\hline \multicolumn{2}{|r|}{ was validated by a simulation on MATLAB/Simulink. } \\
\hline \multicolumn{2}{|l|}{ DFIG } \\
\hline \multicolumn{2}{|l|}{ MATLAB/Simulink } \\
\hline \multicolumn{2}{|l|}{ MPPT } \\
\hline \multicolumn{2}{|l|}{ SMC control } \\
\hline \multicolumn{2}{|r|}{ This is an open access article under the $\underline{C C B Y-S A}$ license. } \\
\hline \multicolumn{2}{|l|}{ Corresponding Author: } \\
\hline \multicolumn{2}{|l|}{ Btissam Majout } \\
\hline \multicolumn{2}{|c|}{ LIMAS Laboratory } \\
\hline \multicolumn{2}{|c|}{ Faculty of Sciences Dhar El Mahraz } \\
\hline \multicolumn{2}{|c|}{ Sidi Mohamed Ben Abdellah University, Fez, Morocco } \\
\hline \multicolumn{2}{|c|}{ Email: badre_isai@hotmail.com } \\
\hline
\end{tabular}

\section{INTRODUCTION}

Lately, the use of renewable energies (i.e., wind and solar photovoltaic) to increase in an incredible way thanks to the scarcity of combustibles. Wind energy is supposed to be the best in terms of quality and price [1]. There are several research studies about the wind turbine. In particular, the ones with asynchronous generators. Although, they have a low cost and simple maintenance as advantage but, they require more expensive equipment and complex control. Therefore, in the recent years, the wind turbine system moved towards the doubly-fed induction generator (DFIG) machine which has higher quality and larger power density [2]. Furthermore, the DFIG reduces the mechanical stress by removing the necessity of the multiplicator which improves the system's reliability [3] and decreases the maintenance costs by directly coupling the turbine and the shafts of the generator [4].

Due to the high variability of the wind speed, it's difficult to obtain a satisfactory performance of the Wind turbine System. Recently, this latter is designed to extract the maximum power point (MPP) power from the wind speed, which is commonly known as the maximum power point tracking (MPPT) strategy. Different methods have been developed in order to maintain the operating point of maximum efficiency. The most widespread control strategy is the optimum power/torque tracking, where the use of the proportional and integral (PI) controller. However, this strategy alone doesn't realize a better performance. Hence, there are other control methods such as the backstepping, fuzzy logic, and sliding mode control (SMC) [5], [6]. This paper is repatriated as follows: Section 2 presents the description of the wind system (turbine, DFIG, inverter, DC-bus, and filter). Section 3 discusses the principle of operation of the sliding mode command as 
well as its application on our system. Section 4 shows and interprets the results of the simulation. Finally, a conclusion in Section 5.

\section{MODELING OF WIND SYSTEM BASED ON DFIG}

The conversion chain includes in series a speed multiplier to increase the speed of rotation to about $1500 \mathrm{rpm}$, a doubly fed induction generator (DFIG) operating at variable speed, Three-phase converters adjust the frequency of the wind turbine to that of the electricity grid to which it is connected $(50 \mathrm{~Hz}$ in Morocco) [7]. The transformation of the power of the aerogenerator into kinetic energy then into mechanical energy of rotation is done in two parts: at the turbine rotor (primary shaft), which captures part of the kinetic energy of the wind present to convert it into mechanical energy at the generator rotor (secondary shaft), which obtains mechanical energy and converts it into electrical energy as shown in Figure 1 [8].

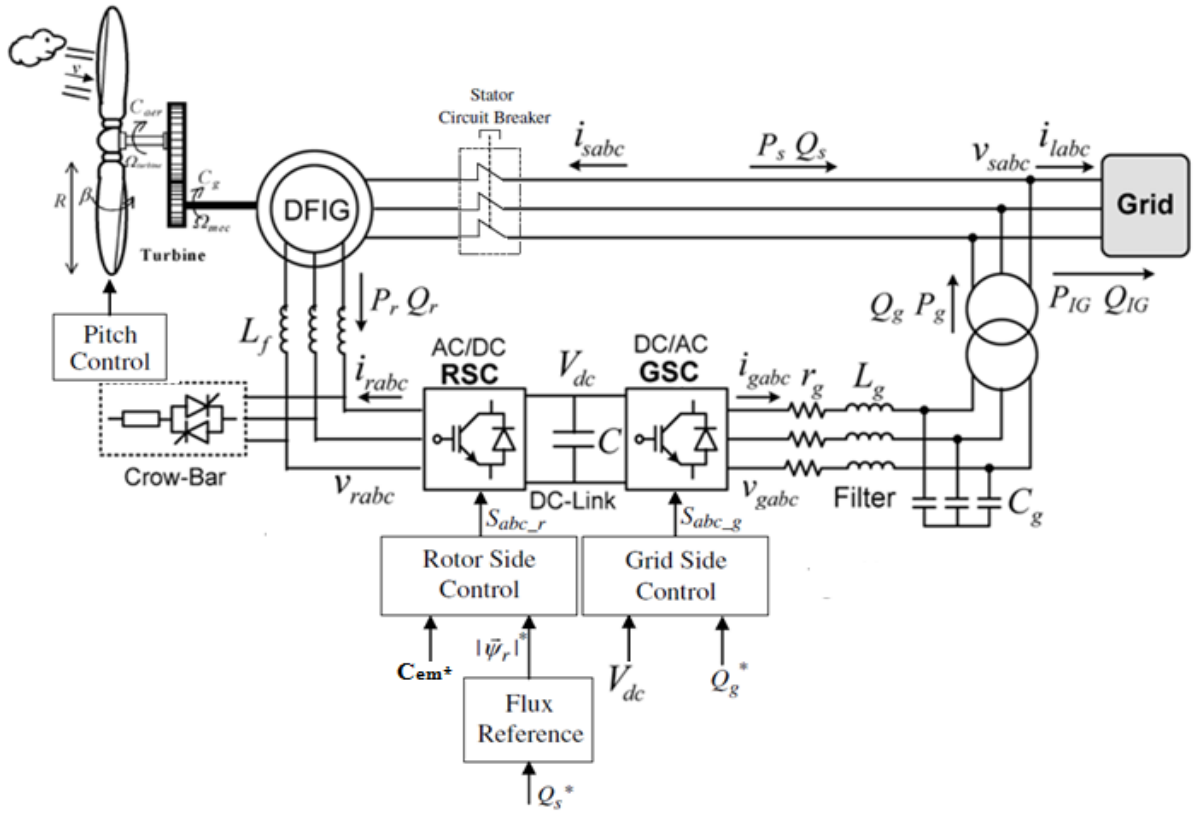

Figure 1. Architecture of the control

\subsection{Wind-turbine model}

The model of the turbine is modeled from the following system of equations (1)-(9) [9], [10]:

$$
\begin{aligned}
& P_{\text {incident }}=\frac{1}{2} \cdot \rho \cdot S \cdot v^{3} \\
& P_{\text {extracted }}=\frac{1}{2} \cdot \rho \cdot S \cdot C_{p}(\lambda, \beta) \cdot v^{3} \\
& \lambda=\frac{\Omega_{t} \cdot R}{v} \\
& C_{p}^{\max }(\lambda, \beta)=\frac{16}{27} \approx 0.593 \\
& C_{p}(\lambda, \beta)=c_{1} \cdot\left(c_{2} \cdot \frac{1}{A}-c_{3} \cdot \beta-c_{4}\right) \cdot e^{-c_{5} \frac{1}{A}}+c_{6} \cdot \lambda \\
& \frac{1}{A}=\frac{1}{\lambda+0.08 \cdot \beta}-\frac{0.035}{1+\beta^{3}}
\end{aligned}
$$




$$
\begin{aligned}
& C_{a l}=\frac{P_{e o l}}{\Omega_{t}}=\frac{1}{2} \cdot \rho \cdot S \cdot C_{p}(\lambda, \beta) \cdot v^{3} \cdot \frac{1}{\Omega_{t}} \\
& J=\frac{J_{t u r}}{G^{2}}+J_{g} \\
& J \frac{d \Omega_{m e c}}{d t}=C_{m e c}=C_{a r}-C_{e m}-f \cdot \Omega_{m e c}
\end{aligned}
$$
[11], [12].

The Figure 2 shows the evolution of the power coefficient as a function of $\lambda$ for different values of $\beta$

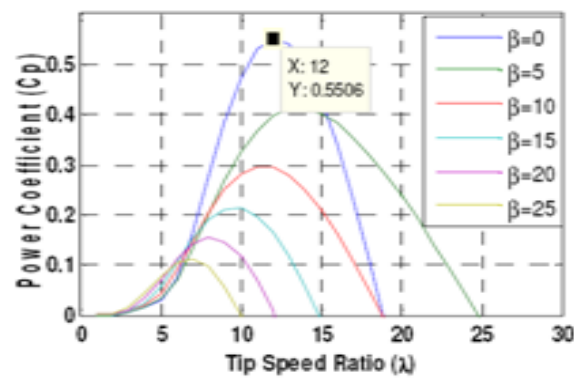

Figure 2. Evolution of the coefficient $\mathrm{Cp}$ as a function of the specific speed $\lambda$

\subsection{Maximization of power control without speed control}

While the variation of the wind speed in steady state is low compared to the electrical time constants of the system, we assume that the speed of rotation of the DFIG is fixed and neglecting the effect of the viscous torque $f$, the dynamic equation of the turbine becomes (12). From (12) we obtain the static equation describing the stationary state of the turbine (13). The reference electromagnetic torque is determined from an estimate of the aerodynamic torque given by (14) and we obtain equation (15). The orientation angle of the blades $\beta$ is assumed to be constant and the estimated speed of the turbine is calculated from the mechanical speed (16). The estimated wind speed is given by equation (17). On the base of the previous equations, we can then write the equation of the reference electromagnetic couple (18) [13], [14].

$$
\begin{aligned}
& J_{\text {tot }} \cdot \frac{d \Omega_{m e c}}{d t}=C_{g}-C_{e m}-f . \Omega_{m e c}=0 \\
& C_{g}=C_{e m}=\frac{C_{\text {aero }}}{G} \\
& C_{\text {aero }_{\text {est }}}=\frac{1}{2 \cdot \Omega_{t_{\text {est }}}} \cdot C_{p_{\text {max }}}\left(\lambda_{\text {opt }}, \beta\right) \cdot \rho \cdot \pi \cdot R^{2} \cdot v_{\text {est }}^{3} \\
& C_{\text {em }}=\frac{C_{\text {aero }} \text { est }}{G} \\
& \Omega_{t_{e s t}}=\frac{\Omega_{m e c}}{G} \\
& v_{\text {est }}=R \cdot \frac{\Omega_{e s t}}{\lambda_{\text {opt }}} \\
& C_{\text {em_ref }}=\frac{\rho \cdot \pi \cdot R^{5} \cdot C_{p \_ \text {max }}\left(\lambda_{o p t}\right) \cdot \Omega_{m e c}^{2}}{2 \cdot \lambda_{o p t}^{3} \cdot G^{3}}
\end{aligned}
$$

\subsection{DFIG model}

The equations of the DFIM in the reference of Park are written as [15], [16]:

- Voltages at the stator: 


$$
\left\{\begin{array}{l}
V_{s d}=R_{s} \cdot i_{s d}+\frac{d \psi_{s d}}{d t}-\omega_{s} \cdot \psi_{s q} \\
V_{s q}=R_{s} \cdot i_{s q}+\frac{d \psi_{s q}}{d t}+\omega_{s} \cdot \psi_{s d}
\end{array}\right.
$$

- Voltages at the stator:

$$
\left\{\begin{array}{l}
V_{r d}=R_{r} \cdot i_{r d}+\frac{d \psi_{r d}}{d t}-\omega_{r} \cdot \psi_{r q} \\
V_{r q}=R_{r} \cdot i_{r q}+\frac{d \psi_{r q}}{d t}+\omega_{r} \cdot \psi_{r d}
\end{array}\right.
$$

With: $\omega_{s}-\omega_{r}=p . \omega$

The magnetic equations are expressed by the flux expressions in the reference (d, q) [3] [17].

- $\quad$ Flux at the stator:

$$
\left\{\begin{array}{l}
\psi_{s d}=L_{s} \cdot \psi_{s d}+M \cdot i_{r d} \\
\psi_{s q}=L_{s} \cdot \psi_{s q}+M \cdot i_{r q}
\end{array}\right.
$$

- $\quad$ Flux at the rotor:

$$
\left\{\begin{array}{l}
\psi_{r d}=L_{r} \cdot \psi_{r d}+M \cdot i_{s d} \\
\psi_{r q}=L_{r} \cdot \psi_{r q}+M \cdot i_{s q}
\end{array}\right.
$$

With: $M=M_{s r}=M_{r s}$

The electromagnetic torque is expressed as a function of the currents and the flows by [18]:

$$
\left\{\begin{array}{l}
C_{e m}=p \cdot\left(\psi_{s d} \cdot i_{s q}+\psi_{s q} \cdot i_{s d}\right) \\
C_{e m}=p \cdot\left(\psi_{r q} \cdot i_{r d}-\psi_{r d} \cdot i_{r q}\right)
\end{array}\right.
$$

The fundamental equation of dynamics is:

$$
C_{e m}=C_{r}+J \cdot \frac{d \Omega}{d t}+f . \Omega
$$

$V_{s(d, q)}, V_{r(d, q)}:$ Stator and rotor voltages in the reference of Park.

$I_{s(d, q),} I_{r(d, q)} \quad$ : Stator and rotor currents in the reference of Park.

$\psi_{s(d, q),} \psi_{r(d, q)}$ : Stator and rotor flux in the reference of Park.

The Figure 3 presents the model of the DFIG machine on Simulink
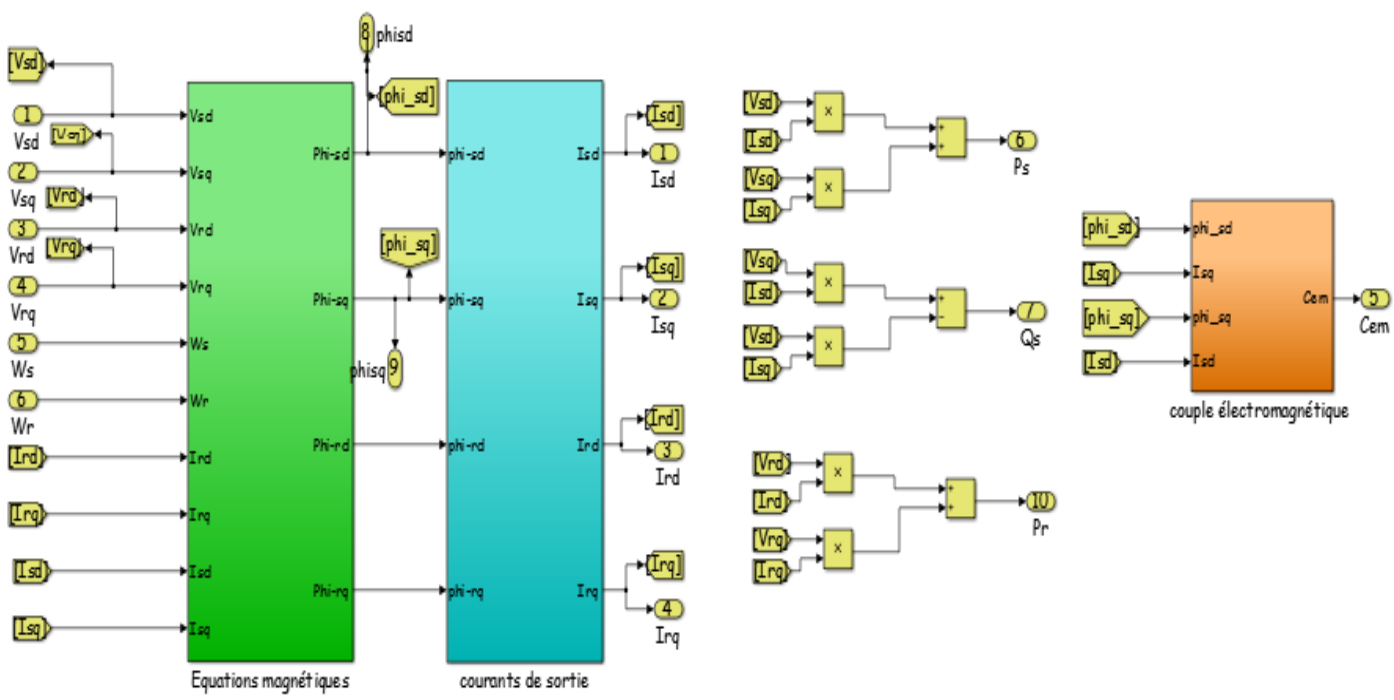

Figure 3. DFIG model simulink 


\subsection{Model of the two-level voltage inverter}

To connect the generator which undergoes a variable speed with the network, it is necessary to go through a stage of power electronics in order to control the power injected. we use 2 RSC and GSC conversion stages, converters which consists of IGBTs as shown in Figure 4.

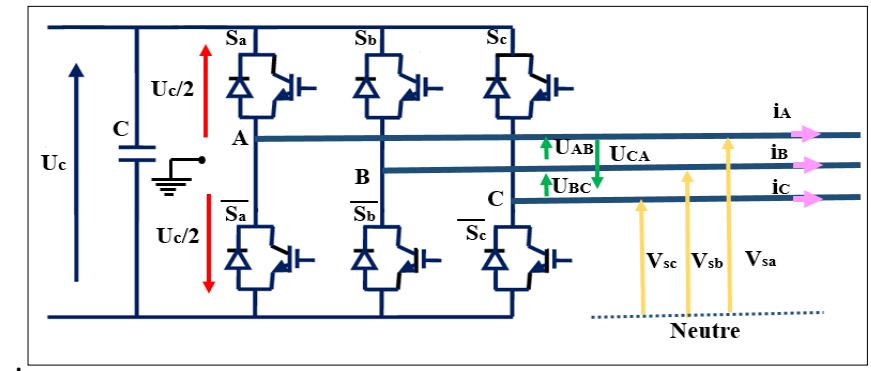

Figure 4. Diagram of the two-level inverter

The $\mathrm{Sa}, \mathrm{Sb}, \mathrm{Sc}$ is the state of the upper switches of each arm of the inverter.

- The expression of the simple voltages is presented by the following system [19]:

$$
\left\{\begin{array}{l}
v_{A}=\frac{1}{3}\left(U_{A B}-U_{C A}\right)=\frac{1}{3}\left(2 \cdot v_{A}-v_{B}-v_{C}\right) \\
v_{B}=\frac{1}{3}\left(U_{B C}-U_{A B}\right)=\frac{1}{3}\left(2 \cdot v_{B}-v_{A}-v_{C}\right) \\
v_{C}=\frac{1}{3}\left(U_{C A}-U_{B C}\right)=\frac{1}{3}\left(2 \cdot v_{C}-v_{A}-v_{B}\right)
\end{array}\right.
$$

- The matrix form of simple tensions becomes [20]:

$$
\left[\begin{array}{l}
v_{A} \\
v_{B} \\
v_{C}
\end{array}\right]=\frac{1}{3}\left[\begin{array}{ccc}
2 & -1 & -1 \\
-1 & 2 & -1 \\
-1 & -1 & 2
\end{array}\right] \cdot\left[\begin{array}{c}
v_{A O} \\
v_{B O} \\
v_{C O}
\end{array}\right]
$$

we associated with Each arm of the inverter a binary command value $\mathrm{Si}$, where $\mathrm{i}=\mathrm{a}, \mathrm{b}, \mathrm{c}$ :

$$
\left[\begin{array}{l}
v_{A O} \\
v_{B O} \\
v_{C O}
\end{array}\right]=\frac{U_{C C}}{2}\left[\begin{array}{l}
S_{a} \\
S_{b} \\
S_{c}
\end{array}\right]
$$

we replace (24) in (23), we get:

$$
\left[\begin{array}{l}
v_{A} \\
v_{B} \\
v_{C}
\end{array}\right]=\frac{U_{C C}}{6} \cdot\left[\begin{array}{ccc}
2 & -1 & -1 \\
-1 & 2 & -1 \\
-1 & -1 & 2
\end{array}\right] \cdot\left[\begin{array}{l}
S_{a} \\
S_{b} \\
S_{C}
\end{array}\right]
$$

The single voltages of the inverter become proportional to the states of the control quantities of the switches $(\mathrm{Sa}, \mathrm{Sb}, \mathrm{Sc})$.

\subsection{DC-bus model}

The DC bus as shown in Figure 5 interconnects the two converters of the wind system (RSC and GSC). The latter allows the transfer of power between two sources at different frequencies. It is modeled by (26) [21].

$$
\left\{\begin{array}{l}
W_{d c}=\int P_{c} \cdot d t=\frac{1}{2} \cdot C \cdot V_{d c}^{2} \\
\frac{d V_{d c}^{2}}{d t}=\frac{2}{c}\left(P_{f}-P_{r}\right)
\end{array}\right.
$$




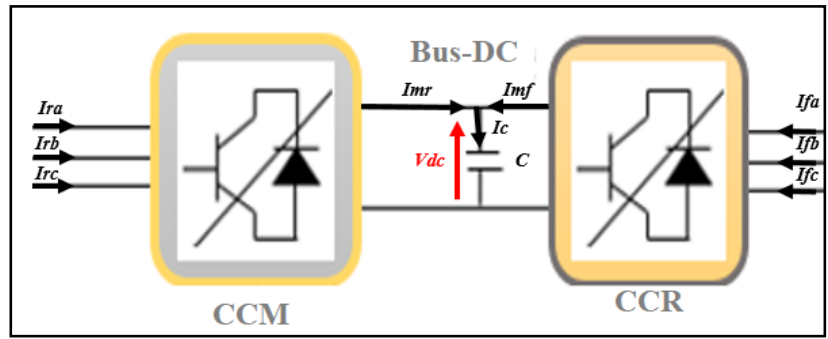

Figure 5. Diagram of the continuous bus

\subsection{RL filter model}

The intermediate filter used is of the RL type. The currents passed between the GSC converter and the network are imposed by the coils constituting the low pass filter. The expressions of the voltages at the terminals of the filters in the the park referential are presented by (27).

$$
\left\{\begin{array}{c}
v_{d f}=-R_{f} \cdot I_{d f}-L_{f} \cdot \frac{d I_{d f}}{d t}+\omega_{s} \cdot L_{f} \cdot I_{q f} \\
v_{q f}=-R_{f} \cdot I_{q f}-L_{f} \cdot \frac{d I_{q f}}{d t}-\omega_{s} \cdot L_{f} \cdot I_{d f}+v_{s}
\end{array}\right.
$$

\section{SLIDING MODE CONTROLLER}

The basic idea of sliding mode control design is first to attract the states of the system to a suitably selected region, and then to design a control law that will always keep the system in that region. Where the design of the sliding mode control algorithm is defined by three complementary steps [22]:

\subsection{Choice of sliding surface}

For a non-linear system presented in the following form (28), where A $(x, t)$ and $\mathrm{B}(\mathrm{x}, \mathrm{t})$ are two continuous and uncertain non linear functions assumed to be bounded [23].

$$
\begin{aligned}
& x \dot{(t)}=A(x, t)+B(x, t) u(t) ; x \in R^{n}, u \in R \\
& (x)=\left(\frac{d}{d t}+\delta\right)^{n-1} * e(x) \\
& e(x)=x^{d}-x \\
& x=\left[x, \dot{x}, \ldots x^{n-1}\right]^{T} ; x^{d}=\left[x^{d}, \dot{x}^{d}, \ldots \ldots\right]^{T}
\end{aligned}
$$

\subsection{Convergence and existence conditions}

To make the surface attractive and invariant, we returned to the second theorem of LYAPUNOV where the scalar function is defined positive by (31). The derivative of this function gives (32), and to guarantee the existence of the sliding mode, where the sliding variable $\mathrm{S}(\mathrm{x}, \mathrm{t})$ tends towards zero, it suffices to ensure that (32) is defined negative (33).

$$
\begin{aligned}
& V(x)=\frac{1}{2} \cdot S(x)^{2} \\
& V \dot{(x)}=S(x) \dot{S(x)} \\
& S(x) S(x)<0
\end{aligned}
$$

\subsection{Determination of the law of control}

The control law is defined by the relation (34), With: $\mathrm{u}^{+}$and $\mathrm{u}^{-}$are continuous functions (35) where $\mathrm{u}^{-} \neq \mathrm{u}^{+}$. The control by sliding modes is composed of two terms: $\mathrm{u}_{\mathrm{eq}}$ : the equivalent control vector, $\mathrm{u}_{\mathrm{n}}$ : The stabilizing command [24]. 


$$
\begin{aligned}
& u=u_{e q}+u_{n} \\
& u=\left\{\begin{array}{l}
u^{+}(x) \text { si } s(x, t)>0 \\
u^{-}(x) \text { si } s(x, t)<0
\end{array}\right.
\end{aligned}
$$

3.3.1. Determination of the equivalent command ueq:

$$
\begin{aligned}
& \dot{S(x)}=\frac{d S}{d t}=\frac{\partial S}{\partial x} \cdot \frac{\partial x}{\partial t} \\
& \dot{S(x)}=\frac{d S}{d t}=\frac{\partial S}{\partial x}\left(A(x, t)+B(x, t)\left(u_{e q}+u_{n}\right)\right) \\
& \dot{S(x)}=\frac{d S}{d t}=\frac{\partial S}{\partial x}\left(A(x, t)+B(x, t) u_{e q}\right)+\frac{\partial S}{\partial x} B(x, t) u_{n} \\
& u_{e q}(t)=\left(-\frac{\partial S}{\partial x} A(x, t)\right)\left(\frac{\partial S}{\partial x} B(x, t)\right)^{-1}
\end{aligned}
$$

\subsubsection{Determination of the basic discontinuous command $u_{n}$ :}

The simplest discontinuous command $\mathrm{u}_{\mathrm{n}}$ is given by (40), where $\mathrm{K}$ is the command gain. This type of control has a drawback known by "CHATTERING". To solve this problem in this case we replaced the "SIGN" function by the "SAT" function [25]:

$$
\begin{aligned}
& u_{n}=K \cdot \operatorname{sign}(S(x)) \\
& \operatorname{Sat}(S)=\left\{\begin{array}{l}
\operatorname{Sat}(S)=1 \text { si } S>\varepsilon \\
\operatorname{Sat}(S)=-1 \text { si } S<\varepsilon \\
\operatorname{Sat}(S)=\frac{S}{\varepsilon} \text { si }|S|<\varepsilon
\end{array}\right.
\end{aligned}
$$

\section{APPLICATION OF THE SLIDING MODE COMMAND TO THE DFIG}

\subsection{Control of the converter on the DFIG (RSC) side and on the network side (GSC)}

Considering the sliding surface proposed by SLOTINE (42), For $n=1$; the sliding surface of the active and reactive power is given by (43), where $P_{\text {sref }}$ and $Q_{\text {sref }}$ are the references of stator powers (active and reactive) of DFIG and $\mathrm{Q}_{\text {fref }}$ and $\mathrm{P}_{\text {fref }}$ are the references of powers (reactive and active) of RL filter [26].

$$
\begin{gathered}
\left\{\begin{array}{c}
S\left(P_{s}\right)=e_{1}=P_{\text {sref }}-P_{s} \\
S\left(Q_{s}\right)=e_{2}=Q_{\text {sref }}-Q_{s} \\
S\left(P_{f}\right)=e_{3}=P_{\text {fref }}-P_{f} \\
S\left(Q_{f}\right)=e_{4}=Q_{\text {fref }}-Q_{f}
\end{array}\right. \\
\left\{\begin{array}{c}
S\left(\dot{P}_{S}\right)=\dot{e}_{1}=\dot{P}_{\text {sref }}-\dot{P}_{s} \\
S\left(\dot{Q}_{s}\right)=\dot{e}_{2}=\dot{Q}_{\text {sref }}-\dot{Q}_{s} \\
S\left(\dot{P}_{f}\right)=\dot{e}_{3}=\dot{P}_{\text {fref }}-\dot{P}_{f} \\
S\left(\dot{Q}_{f}\right)=\dot{e}_{4}=\dot{Q}_{\text {fref }}-\dot{Q}_{f}
\end{array}\right.
\end{gathered}
$$

with:

$$
\left\{\begin{array}{c}
\dot{P}_{s}=-\frac{v_{s} \cdot M}{L_{s}} \dot{I}_{r q} \\
\dot{Q}_{s}=\frac{v_{s}^{2}}{\omega_{s} \cdot L_{s}}-\frac{v_{s} \cdot M}{L_{s}} \dot{I}_{r d} \\
\dot{I}_{r d}=\frac{V_{r d}}{L_{r} \cdot \sigma}-\frac{R_{r}}{L_{r} \cdot \sigma} \cdot I_{r d}+\omega_{r} \cdot I_{r q} \\
\dot{I}_{r q}=\frac{V_{r q}}{L_{r} \cdot \sigma}-\frac{R_{r}}{L_{r} \cdot \sigma} \cdot I_{r q}-\omega_{r} \cdot I_{r d}-\omega_{r} \cdot \frac{M \cdot V_{s}}{L_{r} \cdot L_{s} \cdot \sigma \cdot \omega_{s}}
\end{array}\right.
$$

We replace each term by its expression given by (44), the derivative of the sliding surface becomes as (45) and (46) [27]. 


$$
\begin{gathered}
\left\{\begin{array}{c}
\dot{e}_{1}=\dot{P}_{\text {sref }}+\frac{V_{s} \cdot M}{L_{s}}\left(\frac{V_{r q e q}+V_{r q n}}{L_{r} \cdot \sigma}-\frac{R_{r}}{L_{r} \cdot \sigma} I_{r q}-\omega_{r} I_{r d}-\omega_{r} V_{s} \frac{M}{L_{r} \cdot L_{s} \cdot \omega_{s} \cdot \sigma}\right) \\
\dot{e}_{2}=\dot{Q}_{s r e f}+\frac{V_{s} \cdot M}{L_{s}}\left(\frac{V_{r d e q}+V_{r d n}}{L_{r} \cdot \sigma}-\frac{R_{r}}{L_{r} \cdot \sigma} I_{r d}+\omega_{r} I_{r q}\right)
\end{array}\right. \\
\left\{\begin{array}{c}
\dot{e}_{3}=\dot{P}_{\text {sref }}+\frac{V_{s} \cdot R_{f}}{L_{f}} I_{q f}+\frac{V_{s}\left(V_{f q e q}+V_{f q n}\right)}{L_{f}}+\omega_{s} \cdot V_{s} \cdot I_{d f}-\frac{V_{s}^{2}}{L_{f}} \\
\dot{e}_{4}=\dot{Q}_{s r e f}-\frac{V_{s} \cdot R_{f}}{L_{f}} I_{d f}-\frac{V_{s}\left(V_{f d e q}+V_{f d n}\right)}{L_{f}}+\omega_{s} \cdot V_{s} \cdot I_{q f}
\end{array}\right.
\end{gathered}
$$

According to the sliding mode and the permanent mode, we have (47), (48). The expression of the equivalent Veq command becomes (51) and (52). The stabilizing command is given by (51) and (52). Finally, the expression of the total order $\left(\mathrm{V}_{\mathrm{rd}}, \mathrm{V}_{\mathrm{rq}}\right)$ and $\left(\mathrm{V}_{\mathrm{fd}}, \mathrm{V}_{\mathrm{fq}}\right)$ becomes (53) and (54) [27].

$$
\begin{aligned}
& \left\{\begin{array}{c}
e_{1,2}=0 \\
\dot{e}_{1,2}=0 \\
V_{r d n}=V_{r q n}=0
\end{array}\right. \\
& \left\{\begin{array}{c}
\mathrm{e}_{3,4}=0 \\
\dot{\mathrm{e}}_{3,4}=0 \\
\mathrm{~V}_{\mathrm{fdn}}=\mathrm{V}_{\mathrm{fqn}}=0
\end{array}\right. \\
& \left\{\begin{array}{c}
\mathrm{V}_{\text {rdeq }}=-\frac{\mathrm{L}_{r} \cdot \mathrm{L}_{\mathrm{s}} \cdot \sigma}{\mathrm{M} \cdot \mathrm{V}_{\mathrm{s}}} \dot{\mathrm{Q}}_{\mathrm{sref}}+\mathrm{R}_{\mathrm{r}} \cdot \mathrm{I}_{\mathrm{rd}}-\omega_{\mathrm{r}} \cdot \mathrm{L}_{\mathrm{r}} \cdot \sigma \cdot \mathrm{I}_{\mathrm{rq}} \\
\mathrm{V}_{\text {rqeq }}=-\frac{\mathrm{L}_{\mathrm{r}} \cdot \mathrm{L}_{\mathrm{s}} \cdot \sigma}{\mathrm{M} \cdot \mathrm{V}_{\mathrm{s}}} \dot{\mathrm{P}}_{\text {sref }}+\mathrm{R}_{\mathrm{r}} \cdot \mathrm{I}_{\mathrm{rq}}+\omega_{\mathrm{r}} \cdot \mathrm{L}_{\mathrm{r}} \cdot \sigma \cdot \mathrm{I}_{\mathrm{rd}}+\omega_{\mathrm{r}} \mathrm{V}_{\mathrm{s}} \frac{\mathrm{M}}{\mathrm{L}_{\mathrm{s}} \cdot \omega_{\mathrm{s}}}
\end{array}\right. \\
& \left\{\begin{array}{c}
V_{\text {fdeq }}=\frac{L_{f}}{V_{s}} \dot{Q}_{\text {sref }}-R_{f} \cdot I_{d f}+L_{f} \cdot \omega_{s} \cdot I_{q f} \\
V_{\text {fqeq }}=\frac{L_{f}}{V_{s}} \dot{P}_{s r e f}-R_{f} \cdot I_{q f}-L_{f} \cdot \omega_{s} \cdot I_{d f}+V_{s}
\end{array}\right. \\
& \left\{\mathrm{V}_{\mathrm{rdn}}=\mathrm{K}_{\mathrm{rdn}} \cdot \operatorname{Sat}\left(\mathrm{e}_{1}\right)\right. \\
& \left\{V_{\text {rqn }}=K_{\text {rqn }} \cdot \operatorname{Sat}\left(e_{2}\right)\right. \\
& \int V_{\text {fdn }}=K_{\text {fdn }} \cdot \operatorname{Sat}\left(e_{4}\right) \\
& \left\{\mathrm{V}_{\mathrm{fqn}}=\mathrm{K}_{\mathrm{fqn}} \cdot \operatorname{Sat}\left(\mathrm{e}_{3}\right)\right. \\
& \left\{\begin{aligned}
\mathrm{V}_{\mathrm{rd}}=-\frac{\mathrm{L}_{\mathrm{r}} \cdot \mathrm{L}_{\mathrm{s}} \cdot \sigma}{\mathrm{M} \cdot \mathrm{V}_{\mathrm{s}}} \cdot \dot{\mathrm{Q}}_{\mathrm{sref}} & +\mathrm{R}_{\mathrm{r}} \cdot \mathrm{I}_{\mathrm{rd}}-\omega_{\mathrm{r}} \cdot \mathrm{L}_{\mathrm{r}} \cdot \sigma \cdot \mathrm{I}_{\mathrm{rq}}+\mathrm{K}_{\mathrm{d}} \operatorname{sat}\left(\mathrm{e}_{2}\right) \\
\mathrm{V}_{\mathrm{rq}}=-\frac{\mathrm{L}_{\mathrm{r}} \cdot \mathrm{L}_{\mathrm{s}} \cdot \sigma}{\mathrm{M} \cdot \mathrm{V}_{\mathrm{s}}} \cdot \dot{\mathrm{P}}_{\mathrm{sref}}+ & \mathrm{R}_{\mathrm{r}} \cdot \mathrm{I}_{\mathrm{rq}}+\omega_{\mathrm{r}} \cdot \mathrm{L}_{\mathrm{r}} \cdot \sigma \cdot \mathrm{I}_{\mathrm{rd}}+\omega_{\mathrm{r}} \cdot \mathrm{M} \cdot \frac{\mathrm{V}_{\mathrm{s}}}{\mathrm{L}_{\mathrm{s}} \cdot \omega_{\mathrm{s}}} \\
& +\mathrm{K}_{\mathrm{q}} \operatorname{sat}\left(\mathrm{e}_{1}\right)
\end{aligned}\right. \\
& \left\{\begin{array}{c}
\mathrm{V}_{\mathrm{fd}}=-\frac{\mathrm{L}_{\mathrm{f}}}{\mathrm{V}_{\mathrm{s}}} \cdot \dot{\mathrm{Q}}_{\mathrm{fref}}-\mathrm{R}_{\mathrm{f}} \cdot \mathrm{I}_{\mathrm{df}}+\omega_{\mathrm{s}} \cdot \mathrm{L}_{\mathrm{f}} \cdot \mathrm{I}_{\mathrm{qf}}+\mathrm{K}_{\mathrm{dfn}} \operatorname{sat}\left(\mathrm{e}_{4}\right) \\
\mathrm{V}_{\mathrm{fq}}=-\frac{\mathrm{L}_{\mathrm{f}}}{\mathrm{V}_{\mathrm{s}}} \cdot \dot{\mathrm{P}}_{\mathrm{fref}}-\mathrm{R}_{\mathrm{f}} \cdot \mathrm{I}_{\mathrm{qf}}-\omega_{\mathrm{s}} \cdot \mathrm{L}_{\mathrm{f}} \cdot \mathrm{I}_{\mathrm{df}}+\mathrm{V}_{\mathrm{s}}+\mathrm{K}_{\mathrm{qfn}} \operatorname{sat}\left(\mathrm{e}_{3}\right)
\end{array}\right.
\end{aligned}
$$

\subsection{Simulation \& resuls}

To verify the performance and stability of the control system by SMC control, the DFIG is subject to two robustness tests as shown in Figure 6 (the Tracking and Regulation Tests for SMC and the robustness tests regarding the variation parameters). 

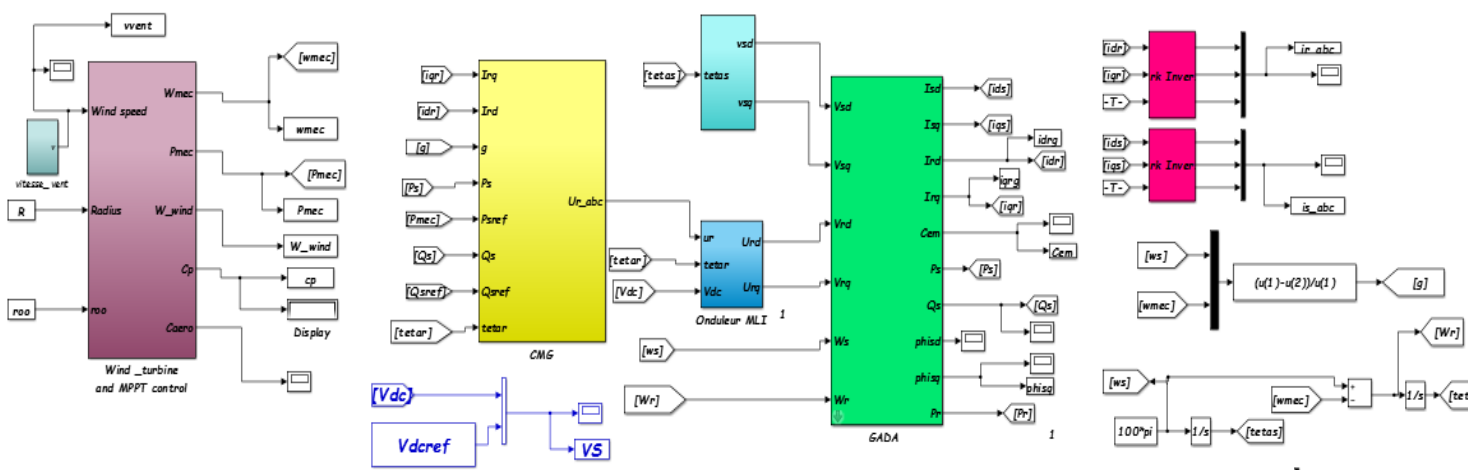

Vdcref $\longrightarrow$ VS
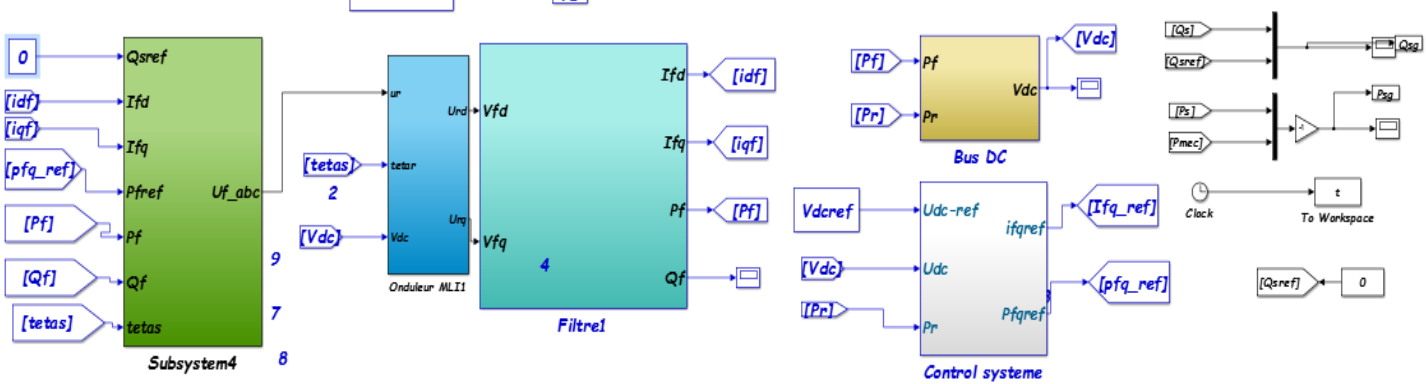

Figure 6. SMC control applied to DFIG wind turbine system

\subsection{Tracking and regulation for $\mathrm{SMC}$}

In this test, we considered the aerodynamic power according to the MPPT as a reference of active power, and zero as reference for reactive power.

\subsubsection{Test with constant speed (rung speed):}

Figure 7 shows the results obtained for the application of the control by Sliding mode to a wind power system at the base of the DFIG.

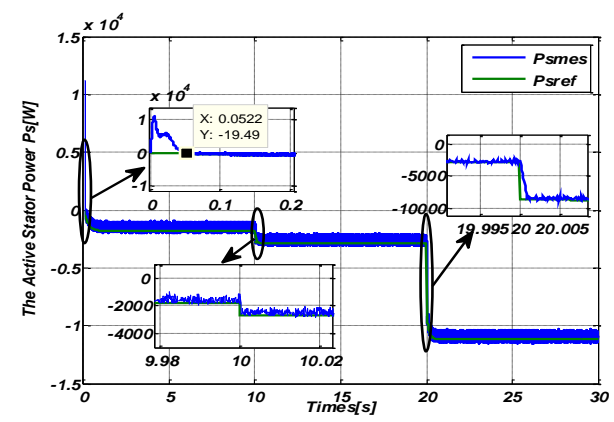

(a)

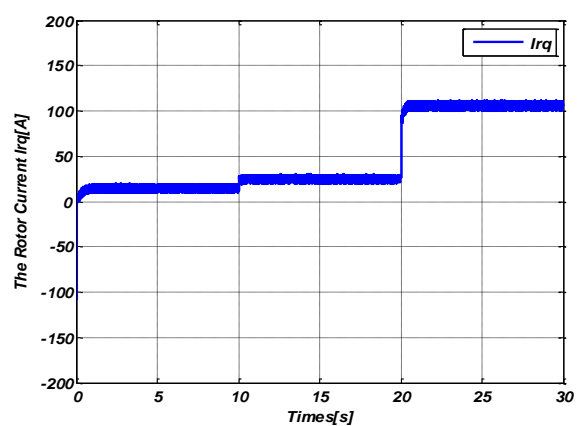

(c)

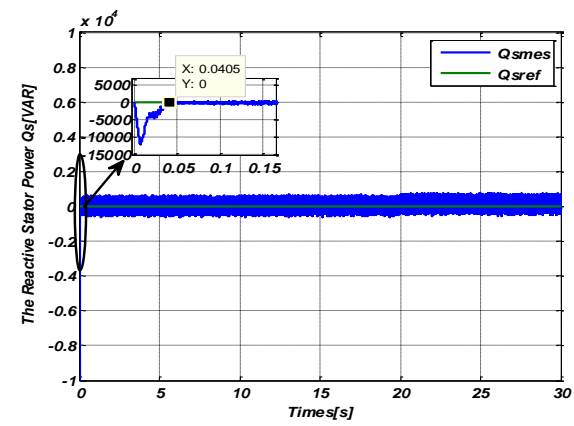

(b)

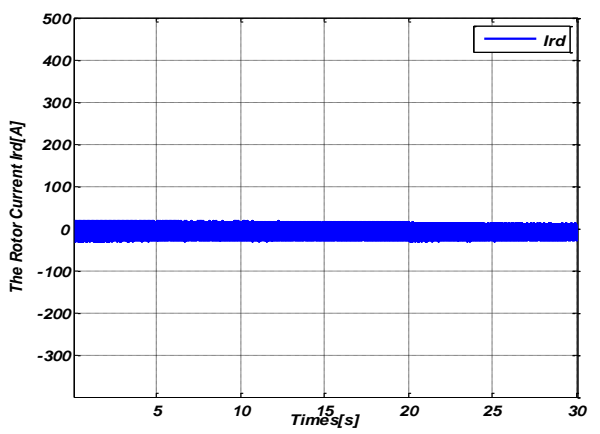

(d) 


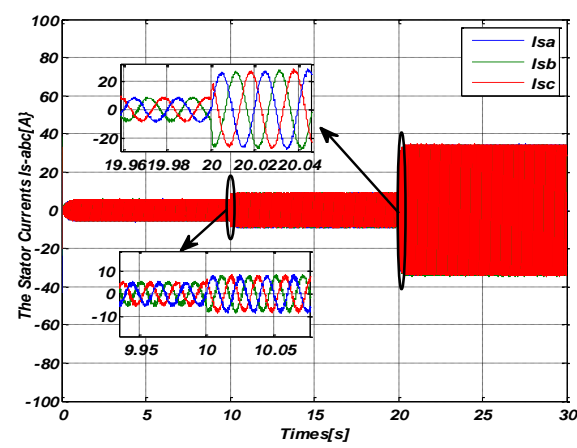

(e)

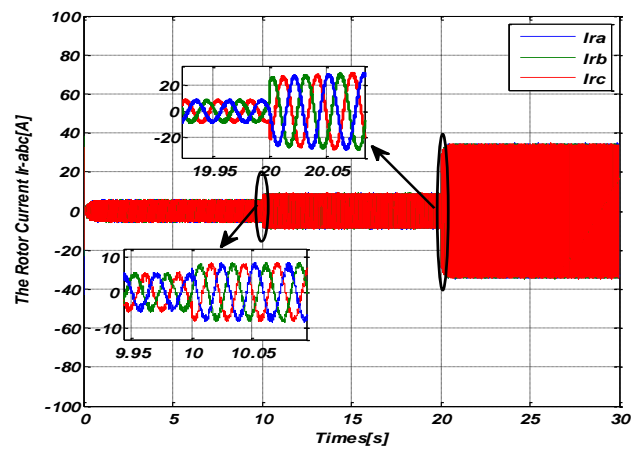

(f)

Figure 7. Results of the control by sliding mode of the DFIG for rung speed; (a) active power ps, (b) reactive power Qs, (c) d-q stator current, (d) dq rotor current, (e) abc stator current, (f) abc rotor current

According to these results, the active powers Ps Figure 7(a) and reactive Qs Figure 7(b) follow the reference. The stator currents Ir Figure 7(c) and the rotor currents Figure 7(d) are of good quality and follow the given instruction. In Figures 7(e) and (f) the stator and rotor currents are sinusoidal with a frequency of $50 \mathrm{~Hz}$, a THD less than 5\%, which implies that the wind power system respects the conditions of connection with the electrical grid.

\subsubsection{Test with variable speed:}

During this test the wind profile illustrated in Figure 8 was applied to the DFIG. According to the curves illustrated in the Figure 8 we notice a good behavior of the machine in spite of the variation of the wind, where the generator follows the references of the powers without overshoot and with an almost zero error. And the electromagnetic torque of the DFIG varies according to the wind speed, and proportional to the active stator power generated. We can notice that in spite of the variations of the wind, the stator current Is-abc remains sinusoidal with a fixed frequency $50 \mathrm{~Hz}$ equivalent to that of the network. The DC bus voltage shows that it follows its reference value quickly without overshooting with a small static error. The slip value $\mathrm{g}$ is negative this implies that the functioning of the DFIG is in hypo-synchronous.

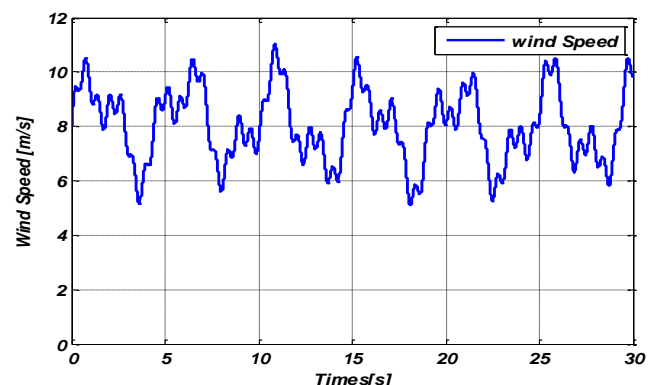

(a)

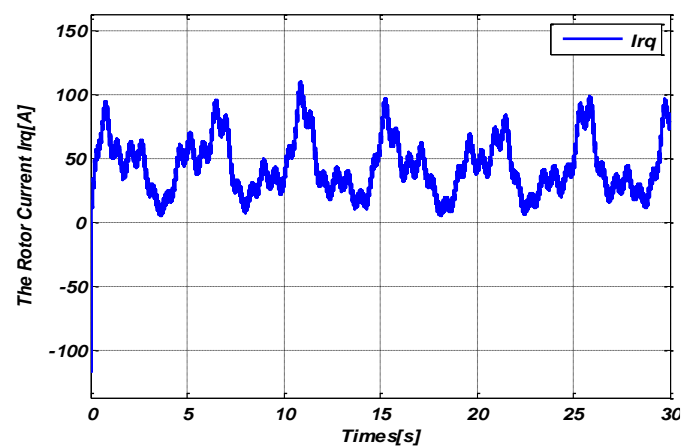

(c)

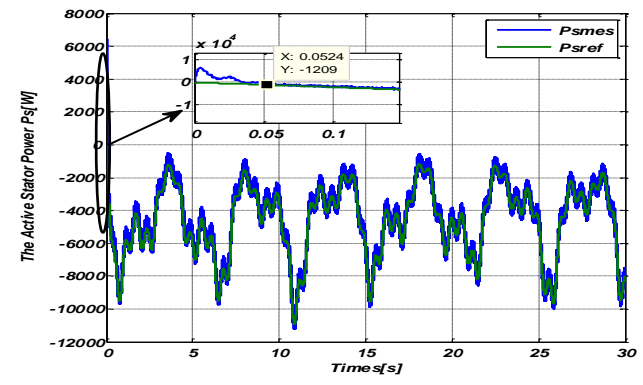

(b)

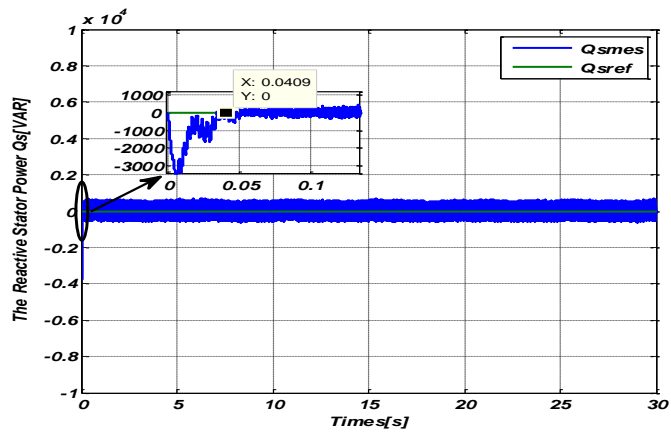

(d) 


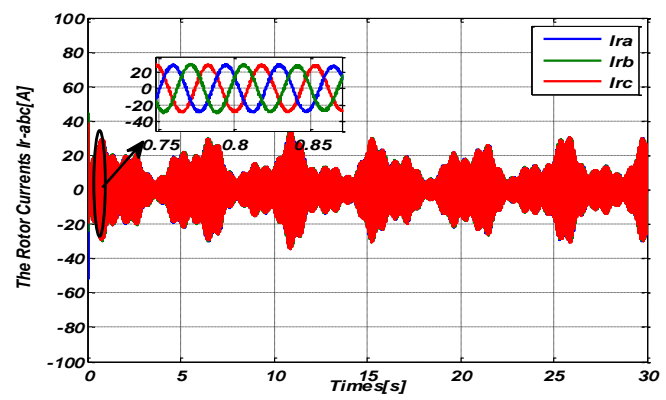

(e)

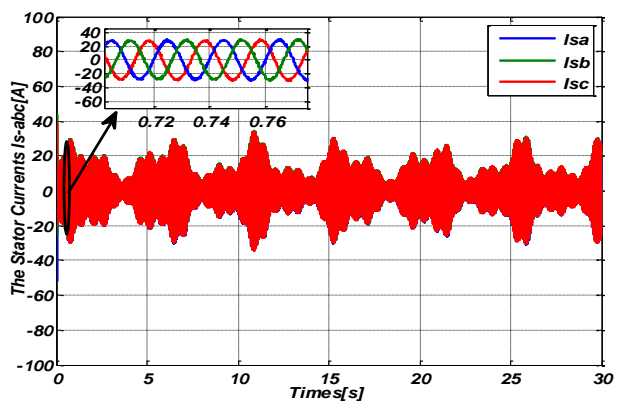

(f)

Figure 8. Results of the control by sliding mode of the DFIG for variable speed; (a) active power Ps, (b) Reactive Power Qs, (c) d-q stator current, (d) dq rotor current, (e) abc stator current, (f) abc rotor current

According to these results, the active powers Ps Figure 8(a) and reactive Qs Figure 8(b) follow the reference. The stator currents Ir Figure 8(c) and the rotor currents Figure 8(d) are of good quality and follow the given instruction. In Figures 8(e) and (f) the stator and rotor currents are sinusoidal with a frequency of $50 \mathrm{~Hz}$, a THD less than 5\%, which implies that the wind power system respects the conditions of connection with the electrical grid. these tests show the validation of our model proposed for the sliding mode technique; in order to validate it complementarily there remains the robustness test (against the parametric variation)

\subsubsection{Robustness tests}

In this test, we varied the parametric variables of the DFIG (resistance RR and Rs) by $+50 \%$ of their nominal values. It is noted that the decoupling between these two powers remains achievable with the same response time despite the variation of the resistance's $\mathrm{Rr}$ and Rs as shown in Figure 9. This shows the robustness of the control by sliding mode facing this variation.
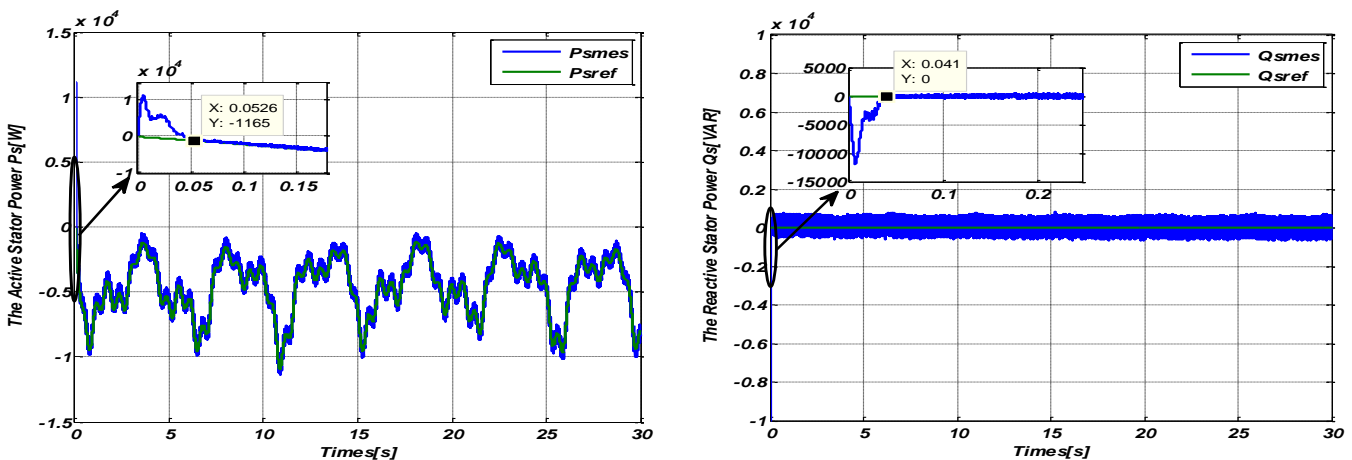

Figure 9. Robustness test with variation of resistances $\mathrm{Rr}$ and $\mathrm{Rs}$ for a variable wind speed

\section{CONCLUSION}

A first sliding order of the sliding mode control has been designed and implemented in order to control the output power of a DFIG generator based-WECS. The simulation results prove that the SMC approach is easy to implement and has a quick response with a robust performance against variations in the wind profile and the disturbances in all the system.

\section{REFERENCES}

[1] Fallahzadeh-Abarghouei, H., Hasanvand, S., Nikoobakht, A., Doostizadeh, M., "Decentralized and hierarchical voltage management of renewable energy resources in distribution smart grid," International Journal of Electrical Power \& Energy Systems, vol. 100, pp. 117-128, 2018.

[2] B. Bossoufi, S. Ionita, H. Alami Arroussi, M. El Ghamrasni, Y. Ihedrane, "Managing voltage drops a variable speed wind turbine connected to the grid," IJAAC International Journal of Automation and Control, vol. 11, no. 1, pp. 15-34, J2017. 
[3] I. El Karaoui, M. Maaroufi, B. Bossoufi, "Robust power control methods for wind turbines using DFIG-generator," International Journal of Power Electronics and Drive System (IJPEDS), vol. 10, no. 4, pp. 2101-2117, 2019.

[4] B. Bossoufi, M. Karim, A. Lagrioui, M. Taoussi, A. Derouich, "Observer Backstepping control of DFIGGenerators for Wind Turbines Variable-Speed: FPGA-Based Implementation,” Renewable Energy, vol. 81, pp. 903-917, 2015.

[5] B. Bossoufi, H. Alami Aroussi, El. M. Ziani, A. Lagrioui, A. Derouich, "Low-Speed Sensorless Control of DFIG Generators Drive for Wind Turbines System," WSEAS Transactions on Systems and Control, vol. 9, no. 4, pp. 514-525, 2014.

[6] B. Bossoufi, M. Karim, A. Lagrioui, M. Taoussi, "FPGA-Based Implementation nonlinear Backstepping control of a PMSM Drive," International Journal of Power Electronics and Drive System (IJPEDS), vol. 4, no. 1, pp. 12-23, 2014.

[7] Fantino, R., Solsona, J., Busada, C., "Nonlinear observer-based control for PMSG wind turbine," Energy, vol. 113, pp. 248-257, 2016.

[8] Liu, Y., Wang, Z., Xiong, L., Wang, J., Jiang, X., Bai, G., et al., "DFIG wind turbine sliding mode control with exponential reaching law under variable wind speed," International Journal of Electrical Power \& Energy Systems, vol. 96 , pp. $253-260.2018$.

[9] H. Alami Aroussi, El. M. Ziani, M. Bouderbala, B. Bossoufi, "Improvement of Direct Torque Control Applied to Doubly Fed Induction Motor Under Variable Speed," International Journal of Power Electronics and Drive System, (IJPEDS), vol. 11, no. 1, pp. 97-106, 2020.

[10] H. Alami Aroussi, El.M. Ziani, M. Bouderbala, B. Bossoufi, "Enhancement of the direct power control applied to DFIG-WECS," International Journal of Electrical and Computer Engineering (IJECE), vol. 10, no. 1, pp. 35-46, 2020.

[11] Y. Ihedrane, C. El Bekkali, M. EL Ghamrasni, S. Mensou, B. Bossoufi, "Improved Wind System using non-linear Power Control," Indonesian Journal of Electrical Engineering and Computer Science (IJEECS), vol. 14, no. 3, pp. 1148-1158, 2019.

[12] Dragomir, G., Şerban, A., Năstase, G., Brezeanu, and A. I., "Wind energy in Romania: A review from 2009 to 2016," Renewable and Sustainable Energy Reviews, vol. 64, pp. 129-143, 2016.

[13] Abderazak, S., Farid, N., "Comparative study between Sliding mode controller and Fuzzy Sliding mode controller in a speed control for doubly fed induction motor," 2016 4th International Conference on Control Engineering \& Information Technology (CEIT), Hammamet, 2016, pp. 1-6.

[14] S. Wang, J. Hu, and X. Yuan, "Virtual synchronous control for gridconnected DFIG-based wind turbines," IEEE Journal of Emerging and Selected Topics in Power Electronics, vol. 3, no. 4, pp. 932-944, 2015.

[15] Z. Zhang, Y. Zhao, W. Qiao and L. Qu, "A Space-Vector-Modulated Sensorless Direct-Torque Control for DirectDrive PMSG Wind Turbines," in IEEE Trans on Industry Applications, vol. 50, no. 4, pp. 2331-2341, 2014.

[16] Abderrahim Zemmit, Sabir Messalti, Abdelghani Harrag, "A new improved DTC of doubly fed induction machine using GA-based PI controller,” Ain Shams Engineering Journal, vol. 9, no. 4, pp. 1877-1885, 2018,

[17] A. A. Eshkaftaki, A. Rabiee and S. T. Boroujeni, "An Applicable Method to Improve Transient and Dynamic Performance of Power System Equipped with DFIG-based Wind Turbines," IEEE Transactions on Power Systems, vol. 35, no. 3, pp. 2351-2361, 2020.

[18] F. El Hammouchi, L. El Menzhi, A. Saad, Y. Ihedrane, B. Bossoufi, "Wind turbine doubly-fed asynchronous machine diagnosis defects using stator and rotor currents lissajous curves," International Journal of Power Electronics and Drive System, (IJPEDS), vol. 10, no. 2, pp. 961-971, 2019.

[19] Y. Ihedrane, C. El Bekkali, M. El Ghamrasni, S. Mensou, B. Bossoufi, "Improved Wind System using non-linear Power Control," Indonesian Journal of Electrical Engineering and Computer Science (IJEECS), vol. 14, no. 3, pp. 1148-1158, 2019.

[20] M. Bouderbala, B. Bossoufi, A. Lagrioui, M. Taoussi, H. Alami Aroussi, Y. Ihedrane, "Direct and indirect vector control of a doubly fed induction generator based in a wind energy conversion system," International Journal of Electrical and Computer Engineering (IJECE), vol. 9, no. 3, pp. 1531-1540, 2018.

[21] Y. Ihedrane, C. El Bekkali, B. Bossoufi, "Improved performance of DFIG-Generators for Wind Turbines VariableSpeed," International Journal of Power Electronics and Drive System, (IJPEDS), vol. 9 no. 4, pp. 1875-1890, 2018.

[22] M.Taoussi, M. Karim, B. Bossoufi, D. Hammoumi, A. Lagrioui, "Low-Speed Sensorless Control for Wind Turbine System," WSEAS Transactions on Systems and Control, vol. 12 no. 1, pp. 405-417, 2017.

[23] M.Taoussi, M. Karim, B. Bossoufi, D. Hammoumi, A. Lagrioui, "Speed Variable Adaptive Backstepping Control of the Double-Fed Induction Machine Drive," International Journal of Automation and Control (IJAAC), vol. 10, no.1, pp. 12-33, 2016.

[24] B. Bossoufi, H. Alami Aroussi, El. M. Ziani, A. Lagrioui, A. Derouich, "Low-Speed Sensorless Control of DFIG Generators Drive for Wind Turbines System," WSEAS Transactions on Systems and Control, vol. 9, no. 4, pp. 514-525, 2014.

[25] B. Bossoufi, M. Karim, A. Lagrioui, M. Taoussi, A. Derouich, "Adaptive Backstepping Control of DFIG Generators for Wide-Range Variable-speed Wind Turbines system," Journal of Journal of Electrical Systems (JES), vol. 10, no. 3, pp. 317-330, 2014.

[26] B. Bossoufi, M. Karim, A. Lagrioui, M. Taoussi, M. L. El Hafyani, "Backstepping control of DFIG Generators for Wide-Range Variable-Speed Wind Turbines," International Journal of Automation and Control (IJAAC), vol. 8 no. 2, pp. 122-140, 2014.

[27] B. Beltran, T. Ahmed-Ali and M. E. H. Benbouzid, "High-Order Sliding-Mode Control of Variable-Speed Wind Turbines," in IEEE Transactions on Industrial Electronics, vol. 56, no. 9, pp. 3314-3321, 2009. 